\title{
Combating Obesity One STEP AT A TIME: Why INDIANA SHOULD IMPLEMENT STATEWIDE COMPLETE STREETS LEGISLATION
}

\author{
Samantha R. Chapman*
}

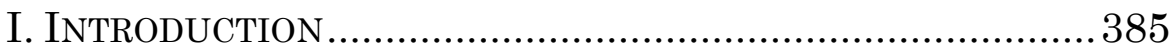

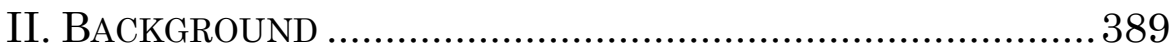

A. The Issue: The Growing Statewide Obesity Rate .....389

B. Complete Streets Outside Indiana ..........................396

C. Complete Streets Across Indiana ............................. 399

D. The Empirical Evidence Base for Built Environment and Complete Streets. 402

E. Additional Benefits of Enacting Complete Streets

Legislation. 410

III. ANALYSIS OF COMPLETE STREETS TO COMBAT HOOSIER

OBESITY

IV. CONCLUSION

\section{INTRODUCTION}

The nation is encountering an epidemic. An epidemic whose numbers continue to rise despite national and statewide efforts to curb its detrimental effects on American society. Indiana is not unaffected by this epidemic. Research shows that Indiana is one of the states hit hardest, as the rate of obesity remains stagnant, just like those affected by it. Although the solution may seem simple, people need to eat less and exercise more; obesity proves to be a much more complex, multi-factored social and medical problem.

Obesity is a growing problem across the nation, especially in the South and Midwest regions of the United States. ${ }^{1}$ Today, about two-thirds of Americans are

* J.D. Candidate, 2015, Indiana University Robert H. McKinney School of Law; B.S., 2012, Manchester College. 
overweight and about one third are obese. ${ }^{2}$ This is such an alarming issue that the Surgeon General asserted that today's youth may be the first generation not to outlive their parents. $^{3}$ In 2012, the Centers for Disease Control and Prevention ("CDC") released a study concluding that nearly $30 \%$ of Indiana adults are obese. 4 Indiana has the eighth highest obesity rate in the United States compared to last year's ranking of fifteenth. ${ }^{5}$ To combat this problem, the CDC provided Indiana along with many other states federal funds to implement a plan to reduce the alarming statistics. The Indiana Healthy Weight Initiative provides Hoosiers with a plan for prevention including information on: childcare and preschool, schools k-12, worksites, healthcare, food environment, built environment, aging population, and breastfeeding. ${ }^{6}$

The built environment aspect of the Indiana Healthy Weight Initiative seeks to facilitate changes to the built environment that support increased levels of physical activity. ${ }^{7}$ Built environment is defined as all of the physical parts of where we live. ${ }^{8}$ This includes homes, buildings, streets, open spaces, and infrastructure. ${ }^{9}$ Decreased levels

1 Barb Berggoetz, Indiana's Adult Obesity Rate Climbs to $8^{\text {th }}$ Worst in U.S., THE INDIANAPOLIS STAR (Aug. 13. 2012, 9:28 PM), http://www.indystar.com/article/20120813/NEWS/120813016/Indiana-sadult-obesity-rate-climbs-8th-worst-U-S-.

2 Julie Wakefield, Fighting Obesity Through the Built Environment, Env'T HEALTH PERSPECTIVES (Aug. 2004), http://www.ncbi.nlm.nih.gov/pmc/articles/PMC1247493.

3 Id.

4 Nat'l Ctr. For Chronic Disease Prevention and Health Promotion, Overweight \& OBesity: Indiana State Nutrition, PhysicAl ACTIVITY, AND OBESITY PROFILE (2012), available at http://www.cdc.gov/obesity/stateprograms/fundedstates/pdf/indianastate-profile.pdf.

5 Berggoetz, supra note 1.

6 New and Noteworthy, InD. HEALThy WEIGHT Initiative, www.inhealthyweight.org/97.htm (last visited Oct. 7, 2013).

7 Id.

8 Impact of the Built Environment on Health, CENTERS FOR DISEASE CONTROL AND PREVENTION (June 2011), http://www.cdc.gov/nceh/publications/factsheets/impactofthebuiltenviron mentonhealth.pdf

9 Id. 
of activity are supported when sidewalks and biking paths are inaccessible or non-existent to people in communities. ${ }^{10}$ The main built environment policy that the Indiana Healthy Weight Initiative supports is called "complete streets." Complete streets are designed and operated to enable safe access for all users: pedestrians, bicyclists, motorists, and public transportation users of all ages and abilities are able to safely move along and across a complete street. 11 Complete streets has become a national movement to ensure that transportation planners and engineers consistently design and operate the entire roadway with all users in mind.12 Leaving streets incomplete means that many people will lack the ability to be active in their daily lives and instead requires people to drive to the places they need to go within the community. The likelihood of obesity rises with increased amount of time spent in the car per day, according to Lawrence Frank, an associate professor of community and regional planning at the University of British Columbia. ${ }^{13}$ Every thirty additional minutes spent in a car was linked to a $3 \%$ increase in obesity in a recent study of 11,000 residents in Atlanta, Georgia. ${ }^{14}$

Although obesity is a multifaceted health issue, complicated by genetic and environmental interactions, the rapid increase in obesity in the last thirty years suggests that largely environmental factors are responsible for this trend. ${ }^{15}$ Samuel Wilson, deputy director of the National Institute of Environmental Health Sciences agreed. "Our built environment promotes a sedentary lifestyle today" and "...if we better understand the linkages between obesity and the built environment, we can create communities and

$10 \quad I d$.

11 Indiana Complete Streets Coalition, HeAlTH BY DESIGN, http://www.healthbydesignonline.org/IndianaCompleteStreetsCampaign .html (last visited Aug. 20, 2014).

12 Complete Streets, CAL. BICYCle COALITION, www.calbike.org/ advocacy/complete-streets/ (last visited Aug. 20, 2014).

13 Wakefield, supra note 2.

14 Id.

15 Id. 
workplaces that promote health and also promote wellbeing, an important feature in overall health."16

Some Indiana communities have determined that complete streets are the answer for improving community connectedness along with promoting physical activity among its members. Bloomington, Madison County, Lake/Porter County, Columbus, Richmond, Evansville, Frankfort, Tippecanoe County, Indianapolis, and Westfield have all adopted complete streets policies between 2009 and 2012.17 Although these local ordinances and resolutions are a step in the right direction, Indiana cannot even begin to make a dent in the state's alarming obesity rate without enacting statewide complete streets legislation. Other states that have implemented statewide complete streets legislation have seen positive outcomes relating to increases in physical activity, along with more connected communities. Leaders and citizens in Indiana must band together to support a uniform policy that will address making streets more complete, so that Hoosiers may have the opportunity to stay physically active in their daily lives. If statewide complete streets legislation fails yet again in the General Assembly, Hoosiers will likely continue to see an increase in their waistlines along with health care costs related to obesity.

First, this note will discuss the issue of obesity and how the epidemic had worsened in the last decade, the health care costs associated with obesity, and specifically the negative health effects that weigh down society. Next, current complete street policies both outside and inside of Indiana will be examined and evaluated for effectiveness. Empirical evidence on the relationship between obesity and built environment will also be reviewed. Statewide complete streets legislation will be examined as a way to improve the state's physical activity rate by providing streets where pedestrians, bicyclists, motorists, and public transportation users feel safe to travel. The history of how these policies have been adopted will also be addressed. Finally, this note will focus on the ways in which Indiana

\footnotetext{
$16 I d$.

17 Indiana Complete Streets Coalition, supra note 11.
} 
could benefit from implementing statewide complete streets legislation to combat the high state obesity rate by increasing physical activity, along with various other aspects of Hoosier health.

\section{BACKGROUND}

\section{A. The Issue: The Growing Statewide Obesity Rate}

Obesity is defined by the Centers for Disease Control and Prevention ("CDC") as a weight that is greater than what is generally considered healthy for a person of a certain height. 18 Determining if an individual is overweight or obese occurs by calculating his or her body mass index ("BMI"). BMI is used as an indicator because it correlates with a person's amount of body fat. ${ }^{19}$

In 2012, the CDC released a study indicating that among Indiana adults over eighteen years of age, $65.9 \%$ of adults were overweight with a BMI of over twenty-five and $29.6 \%$ of adults were obese with a BMI of over thirty. ${ }^{20}$ Among Indiana adolescents, enrolled in grades nine through twelve, $15.9 \%$ were overweight and $12.8 \%$ were obese. ${ }^{21}$ Among Indiana children, ages two to five, $16.6 \%$ were overweight and $14.2 \%$ were obese. ${ }^{22}$ This amounts to over 1.5 million Hoosiers being classified as obese. ${ }^{23}$ In regard to physical activity, the study found that $27.2 \%$ of adults had not participated in any physical activity in the past month and only $43.2 \%$ of adults had achieved at least 300 minutes per week moderate intensity physical activity or 150

18 Defining Overweight and Obesity, Centers for Disease Control \& PREVENTION, http://www.cdc.gov/obesity/adult/defining.html (last visited Aug. 20, 2014).

19 Id.

20 Nat'L Ctr. For Chronic Disease Prevention and Health PROMOTION, supra note 4.

21 Id.

$22 I d$.

23 United Health Found., State Data > Indiana, AMERICA's HeALTH RANKINGS, http://www.americashealthrankings.org/IN (last visited Aug. $22,2014)$. 
minutes per week of vigorous-intensity physical activity. ${ }^{24}$ Overall, one in four Indiana adults remain inactive. ${ }^{25}$

Obesity is a condition correlated with genetics and a person's environment. Thirty to forty percent of obesity can be attributed to an individual's genes. ${ }^{26}$ Other factors include diet and energy intake, physical activity, and individual factors. ${ }^{27}$ According to $F$ as in Fat: How Obesity Threatens America's Future 2013, a report from the Trust for America's Health and the Robert Wood Johnson Foundation, region, age, gender, education, and income are also factors associated with obesity. ${ }^{28}$ The report notes that individuals living in the South and Midwest regions of the United States, older individuals, less educated individuals, and individuals with lower incomes have a higher likelihood of being obese. ${ }^{29}$ Physicians recommend a variety of treatment options including: diet, physical activity, behavior modification, medications, and sometimes even surgery in situations where other treatment methods are ineffective. ${ }^{30}$ Each treatment plan must be individually constructed, as people face different obstacles in the weight loss process.

Obesity is linked to heart disease, stroke, diabetes, some cancers, and countless other health problems. ${ }^{31}$ The Indiana State Department of Health released, "The Burden of Obesity Related Cancers and the Promotion of Physical

24 Nat'l Ctr. For Chronic Disease Prevention and Health PROMOTION, supra note 4.

25 United Health Found., supra note 23.

26 Donald D. Hensrud, The OBesity Explosion: How Did We GeT

HERE AND WHERE ARE WE AT? (2013), available at http://kelley.iu.edu/CBLS/files/conferences/Hensrud\%20Obesity\%20Indi ana $\% 2011-22 \% 20$ final.pdf.

27 Id.

28 F as in Fat: How Obesity Threatens America's Future 2013, TRUST FOR AMERICA'S HEALTH, http://healthyamericans.org/report/108/ (last visited Feb. 28, 2014).

29 Id.

30 Id.

31 Nat'l Ctr. for Chronic Disease Prevention and Health PROMOTION, supra note 4. 
Activity in Indiana" in 2014.32 The report identified that not only is obesity an issue in Indiana, but it is also causing higher rates of cancer for Hoosiers. ${ }^{33}$ Estimates suggest that being overweight or obese contributes to $14-20 \%$ of all cancer-related mortality. ${ }^{34}$ The most prevalent cancers related to excess weight include: postmenopausal breast, colon and rectum, endometrial, esophagus, gallbladder, thyroid, kidney, and pancreatic. ${ }^{35}$ The incidence rates of esophageal, pancreatic, kidney and renal, and thyroid cancer have significantly increased in Indiana between 1997 and 2010.36 Cancer is the second leading cause of death in Indiana, just behind heart disease, which also is linked to obesity. 37

Further, the medical costs associated with overweight and obese adults are estimated at 147 billion dollars nationally. ${ }^{38}$ More alarming, obesity is a leading cause of preventable death, claiming 200,000 lives in the United States annually. ${ }^{39}$ Obesity is even more prevalent than smoking and is associated with chronic health conditions, along with overall poor physical health. ${ }^{40}$ Poor diet and physical inactivity are considered to be the biggest lifestyle contributors to obesity in general. ${ }^{41}$

Obesity affects not only the health of Americans, but also the nation's economy. Employers are also increasingly

32 Ind. State Dep't of Health, The Burden of Obesity Related Cancers and the Promotion of Physical Activity in Indiana (2014), IN.GOV, http://www.in.gov/isdh/files/Obesity_Report_2014_(2).pdf.

33 Id. at 4.

34 Id. at 5 .

35 Id. at 6.

$36 \mathrm{Id}$.

37 Indiana: Burden of Chronic Diseases, CEnTERs fOR Disease CONTROL AND PREVENTION, http://www.cdc.gov/chronicdisease/states/ pdf/indiana.pdf (last visited Feb. 28, 2014).

38 Eric A. Finkelstein et al., Annual Medical Spending Attributable to Obesity: Payer-And Service-Specific Estimates, 28 Health AfFaIRS w822, w828 (2009).

39 United Health Found., Obesity: United States, AMERICA'S HEALTH RANKINGS, http://www.americashealthrankings.org/ALL/ Obesity/disparities (last visited Dec. 17, 2014).

40 Id.

41 Id. 
concerned with obesity as an epidemic, due to controlling health care costs and maintaining productive workers. ${ }^{42}$ In 2001 , obesity cost employers $\$ 13$ billion a year, "including $\$ 8$ billion for health insurance, $\$ 2.4$ billion for sick leave, $\$ 1.8$ billion for life insurance, and another $\$ 1$ billion for disability insurance." 43 Obese workers are almost twice as likely to be frequently absent from work than people of a healthy weight according to a study conducted by Brigham Young University health promotion professor, Larry Tucker. ${ }^{44}$ Annually, obesity-related illness costs employers 39.3 million lost work days, 239 million days of reduced productivity, and 62.7 million doctor visits. ${ }^{45}$

The United Health Foundation published its yearly report titled, "America's Health Rankings" in 2012. This report ranks each state based on rates of air pollution, binge drinking, cancer deaths, cardiovascular deaths, children in poverty, diabetes, early prenatal care, geographic disparity, high school graduation rate, immunization coverage, infant mortality, infectious disease, lack of health insurance, obesity, occupational fatalities, poor mental health days, poor physical health days, premature death, preventable hospitalizations, primary care physicians, public health funding, smoking, violent crime, cardiac heart disease, cholesterol check, annual dental visit, diet consisting of fruit and vegetables, heart attack, high blood pressure, high cholesterol, income disparity, low birth weight, low health status, median household income, personal income per capita, physical activity, preterm birth, stoke, teen birth rate, underemployment rate, and unemployment rate. 46 After taking these extensive factors into account, researchers ranked each state overall in the nation. Indiana came out forty-first this year, compared to its rank of thirty-seventh

42 Wakefield, supra note 2.

43 Id.

44 Id.

45 Id.

46 United Health Found., Overall State Rankings, AMERICA'S HEALTH RANKINGS, http://statehealthstats.americashealthrankings.org/ \#/country/US/2011/Overall-State-Ranking (last visited Oct. 8, 2013). 
in 2011.47 When specifically looking at the obesity factor, Indiana is ranked forty-second in the nation, showing an increased obesity rate since even last year. ${ }^{48}$ Additionally, the study shows that factors correlated with Indiana's high obesity ranking include diets low in fruit and vegetables and physical inactivity. 49

In January 2011, one year before the new statistics were released in 2012, the Indiana State Department of Health released a statement, "Indiana Takes Next Step in Tackling Obesity." 50 In the press release, State Health Commissioner, Dr. Gregory Larkin, explained that only $41 \%$ of adolescents and $64 \%$ of adults meet the recommended levels for physical activity. ${ }^{51}$ In addition, obesity and obesity related diseases are costly to the state of Indiana. Medicare and Medicaid pay about half of all costs associated with obesity. ${ }^{52}$ Indiana's obesity-attributable health care spending in 2008 was estimated at $\$ 1.9$ billion or $\$ 435$ per adult. 53 If trends continue, Indiana's obesity attributable health care spending could reach as high as $\$ 7$ billion or $\$ 1,484$ per adult by 2018.54 Indiana must find innovative ways to promote physical activity and healthy lifestyles to ensure that obesity related health care costs remain the same or decline in future years.

In addition to the 2011 press release, the Indiana State Department of Health issued a report titled, "Burden of Obesity in Indiana." Here, Dr. Larkin asserted that Indiana's overweight and obesity rate has increased 13\%

47 United Health Found., State Data > Indiana, AMERICA's HEALTH RANKINGS, http://www.americashealthrankings.org/in (last visited Oct. 8, 2013).

48 United Health Found., supra note 23.

49 Id.

50 Press Release, Ind. State Dep't of Health, Indiana Takes Next Step in Tacking Obesity (Jan. 28, 2011) (available at http://www.in.gov/icw/files/PR_1.28.11.pdf).

51 Id.

52 HensRud, supra note 26.

53 Ind. State Dep't of Health, supra note 50.

54 Id. 
since 1995.55 The study sought to determine which Hoosiers were at the highest risk of becoming overweight or obese and what were the forces behind the increasing rates across the state. ${ }^{56}$ Adult married men between the ages of thirtyfive and seventy-four, not engaging in at least 300 minutes of moderate exercise per week were found to be the highest risk group for adults. ${ }^{57}$ The environmental factors that contribute to the rising levels of obesity include: busy lifestyles; greater access to inexpensive, high-calorie, fatand sugar-laden food; and the convenience and affordability of eating out more often. ${ }^{58}$ In addition, our physical environment does not make basic physical activities, such as walking and riding a bicycle, attractive or safe. The result is a diet poor in fruit and vegetable consumption and a lack of physical activity, two of the major factors that contribute to obesity. ${ }^{59}$

More recently, Indiana's Behavioral Risk Factor Surveillance System ("BRFSS") 60 indicated that only $17.3 \%$ of adults and $24.2 \%$ of high school students were meeting the recommended levels for physical activity in 2012.61 If these trends continue, the obesity rate in Indiana is projected to be at $56 \%$ by $2030 .{ }^{62}$

Indiana's response to these staggering statistics was to create the Indiana Healthy Weight Initiative, which seeks to improve health and quality of life for Indiana residents. ${ }^{63}$ This is part of a five year federal grant from the CDC to improve healthy eating and physical activity in Indiana to

55 IND. STATE DEP'T OF HEALTh, 2011 BURDEN OF OBESITY IN INDIANA 1 (2011), available at http://www.in.gov/isdh/files/ Burden_of_Obesity_FINAL_11_18_2011.pdf.

56 Id.

57 Id.

$58 \mathrm{Id}$.

59 Id.

60 Behavioral Risk Factor Surveillance System ("BRFSS") is the world's largest telephone survey that tracks health risks in the United States.

61 Marcie L. Memmer, Healthy People, Healthy Communities (2013).

62 Id.

63 New and Noteworthy, supra note 6. 
combat the negative effects of obesity. ${ }^{64}$ The Initiative's Task Force developed Indiana's Comprehensive Nutrition and Physical Activity Plan, 2010-2020, which focuses on policy and environment change for obesity prevention and healthier living. ${ }^{65}$

The task force has outlined six goals the plan hopes to achieve.66 These include: increasing access to and consumption of healthy foods and beverages; increasing opportunities for and engagement in physical activity; increasing efforts aimed at enabling people to achieve and maintain a healthy weight across the lifespan; reducing environmental and policy-related disparities for breastfeeding; nutrition; physical activity; overweight; obesity and chronic disease; increasing the capacity of communities and settings within those communities (e.g., schools, worksites, faith-based organizations, etc.) to develop and sustain environmental and policy support systems that encourage healthy eating and active living; and increasing state and local strategic partnerships to more effectively coordinate efforts, share resources, and identify and reach priority populations. ${ }^{67}$ Complete streets policy is part of this initiative and is driven by Health by Design, an Indianapolis based coalition that brings together advocates of community design, transportation, and health to support healthy and active lifestyle choices. ${ }^{68}$

State leaders desperately need to find solutions for obesity, as a costly problem in Indiana, which negatively affects a significant portion of the population. Part of this solution could be statewide complete streets legislation if organizations, community members, and state legislators express its need and priority in the General Assembly.

64 Ind. State Dep't of Health, supra note 50.

65 Nat'L CTR. FOR Chronic Disease Prevention and Health PROMOTION, supra note 4.

66 Ind. State Dep't of Health, supra note 50.

67 Id.

68 Indiana Complete Streets Coalition, supra note 11. 


\section{B. Complete Streets Outside Indiana}

Over 500 complete streets policies have been implemented nationwide. ${ }^{69}$ In 2012 alone, 125 communities adopted complete streets policies. ${ }^{70}$ Communities both small and large have adopted complete streets, showing that these policies are effective in and beneficial to communities of all sizes. Fifty-two percent of the current implemented policies are in suburbs, $26 \%$ in large, midsize, and small cities, and $22 \%$ in small and rural towns. ${ }^{71}$ Additionally, nineteen states have adopted statewide complete streets legislation across the United States, including Colorado, California, and Vermont, to name a few. ${ }^{72}$ Colorado was ranked first for low rates of statewide obesity, compared to California, which ranked tenth, and Vermont, which ranked eighth. ${ }^{73}$ The obesity rate in Colorado is currently $19.1 \%$ and by 2018 is projected to be the only state where less than $30 \%$ of adults are overweight. ${ }^{74}$ Nationally, the Safe Streets Act of 2013 was introduced in the House by Representatives Matsui and Joyce. ${ }^{75}$ As written, the bill would ensure that all users of the transportation system, including people walking, biking, taking public transportation, or driving, as well as children,

69 Smart Growth Am. \& Nat'l Complete Sts. Coal., The Best COMPLETE STREeT POLICIES OF $2012 \quad 3$ (2013), available at http://www.smartgrowthamerica.org/documents/cs-2012-policyanalysis.pdf.

70 Id.

71 Health by Design, Complete Street Policies: Statewide TRends AND DEveloping A POLICY THAT WoRKS 7 (2012), available at http://www.healthbydesignonline.org/documents/CompleteStreetsPolicie sandStatewideTrends_ZiaBrucaya.pdf.

72 Changing Policy Complete Streets Development 101: Presentation, SMART GROWTH AM., http://www.smartgrowthamerica.org/ complete-streets/changing-policy (last visited Sept. 25, 2014).

73 United Health Found., supra note 46.

74 William Sadler, Complete Streets Make Healthier People: Reforming Street Design Policies to Combat Obesity 2, CONGRESS FOR THE NEw URBANISM, http://www.cnu.org/sites/www.cnu.org/ files/sadlerb_cnu18.pdf (last visited Dec. 18, 2014).

75 National Complete Streets Coalition, On the Hill, The Safe Streets Act, SMART GROWTH AM., http://www.smartgrowthamerica.org/ complete-streets/federal-policy/on-the-hill (last visited Sept. 25, 2014). 
older adults, and individuals with disabilities, are able to travel safely and conveniently on our streets. ${ }^{76}$ This legislation did not pass in 2013, but still is receiving support from the National Complete Streets Coalition, which is powered by Smart Growth America.

Vermont enacted complete streets legislation in 2011. Vermont has implemented several design changes with complete streets to promote safety. ${ }^{7}$

These changes include: retiming crossing signals to allow for slower walking speeds; adding/maintaining sidewalks that are connected to services; installing curb ramps, sidewalk seating, and bus shelters with seating; improving lighting, signage with larger fonts, and reflective signs and pavement markings; and protecting left turn lanes with green arrows (this can cut left turn crashes in half). .78

California implemented complete streets with the mission of "improving mobility across California."79 Complete streets in California seek to result in more options for people to go from one place to another; less traffic congestion and greenhouse gas emissions; more walkable communities (with healthier, more active people); and fewer barriers for older adults, children, and people with disabilities. ${ }^{80}$ California also recognizes the economic benefits that complete streets legislation offers. Economically, complete streets helps revitalize communities, giving families

76 Id.

77 Gov. Shumlin Signs Complete Streets Bill, VT., http://governor.vermont.gov/media-complete-streets (last visited Jan. 3, 2014).

78 Id.

79 Complete Streets Program, CAL. DEP'T OF TRANsP., http://www.dot.ca.gov/hq/tpp/offices/ocp/complete_streets.html (last visited Sept. 25, 2014).

$80 \mathrm{Id}$. 
opportunities to lower transportation costs by using public transit, walking or biking to travel to their destinations. ${ }^{81}$

Indiana's neighbor, Michigan, recently enacted statewide complete streets legislation in hopes of reducing its standing of ninth highest state obesity rate in the nation. Like Indiana, the Michigan Department of Community Health created a strategic plan to reduce childhood obesity specifically within the state. ${ }^{82}$ Complete streets quickly became a state initiative that was of highest priority with the Department of Community Health, raising awareness that statewide efforts were underway. ${ }^{83}$ Communities with local complete streets ordinances were vocal to legislators about their support for a statewide complete streets policy. Community members attended legislative hearings, expressing support for complete streets, which caught the attention of Michigan lawmakers. ${ }^{84}$ In 2010, after two years, statewide complete streets legislation was passed requiring the Michigan Department of Transportation to consider all legal users of the roads in its planning from public transportation riders and motorists, to bicyclists and pedestrians. ${ }^{85}$ The Michigan Department of Transportation works with the Michigan Department of Community Health and the Healthy Kids, Healthy Michigan initiative to help plan built environments for local communities and seeks to promote physical activity. This shows that enacting and implementing a statewide complete streets policy takes commitment from both state agencies and community groups.

Complete streets policies have been effective across the nation in re-connecting communities and promoting physical activity, as a way to reduce the nationwide epidemic of obesity. States and localities are greatly

81 Id.

82 Nat'l Ctr. For Chronic Disease Prevention and Health Promotion, Taking it to the (Complete) Streets: Michigan's RoAD TO FIgHT OBESITY (2011), available at http://www.cdc.gov/obesity/downloads/field/stories-from-the-

field_michigan-web_3-7-12.pdf.

83 Id.

84 Id.

85 Id. at 2. 
benefiting from these recently adopted policies geared toward making streets accessible for all users. States like Colorado, California, and Vermont have already increased mobility and physical activity, decreased transportation costs, and effectively revitalized communities in the short time that these statewide policies have been in place. Additionally, the state obesity rates in Colorado, California, and Vermont are much lower than in Indiana. These policies are most successfully implemented when communities unite with the legislature and state agencies to achieve goals that can benefit the state as a whole. This action begins with citizens, grows with support from groups, and gains the most momentum when state agencies get involved. The states with the most accomplished complete street policies worked together as communities to achieve the effort.

\section{Complete Streets Across Indiana}

The Indiana communities of Bloomington, Madison County, Lake/Porter County, Columbus, Richmond, Evansville, Frankfort, Tippecanoe County, Indianapolis, and Westfield have all adopted complete streets policies. Complete streets are now available to $36 \%$ of Hoosiers. ${ }^{86}$ In 2012, The National Complete Streets Coalition named Indianapolis' newly adopted ordinance the best complete streets policy in the nation. ${ }^{87}$ In response to this announcement, Indianapolis Mayor Greg Ballard stated, "We're very proud of our efforts in the past few years to make Indianapolis more walkable, bikeable and connected. The strength of our complete streets plan is its clear commitment to achieving a vibrant, healthy city. Now, we're working to make our plan a reality with safe and accessible transportation options for all residents." 88 Indianapolis' complete streets policy includes improvements

86 IND. CANCER CONSORTIUM, http://indianacancer.org/blog/ completestreetsinfograph/ (last visited Jan. 3, 2015).

87 Indy Tops 'Complete Streets' List, InsIDE IND. Bus. (Apr. 8, 2013) http://www.insideindianabusiness.com/newsitem.asp?ID=58810.

88 Id. 
to sidewalks, bike lanes, special bus lanes, comfortable and accessible transportation stops, frequent and safe crossing opportunities, median islands, accessible pedestrian signals, curb extensions, narrower travel lanes, and roundabouts. ${ }^{89}$ INDYCOG, AARP, and Health by Design made this local initiative possible with the help of other community members. ${ }^{90}$

The National Complete Streets Coalition evaluated the policies nationwide on ten ideal elements. These include: vision and intent, all users and modes, all projects and phases, clear, accountable exceptions, network, jurisdiction, design, context sensitivity, performance measures, and implemented next steps. ${ }^{91}$ The elements are considered the policies that represent the best practices from the research and experience of the National Complete Streets Coalition Steering Committee and workshop instructors. ${ }^{92}$

Indianapolis was highlighted in the coalition's report most distinctly under the "performance measures" element. The policy language reads,

The City shall measure the success of this Complete Streets policy using, but not limited to, the following performance measures: total miles of bike lanes, linear feet of new pedestrian accommodation, number of new curb ramps installed along city streets, crosswalk and intersection improvements, percentage of transit stops accessible via sidewalks and curb ramps (beginning in June 2014), rate of crashes, injuries and fatalities by mode, rate of children walking or bicycling to school (beginning in June 2014). Unless otherwise noted above, within six months of

89 We Have a Complete Streets Ordinance in Indianapolis!, INDYCOG, http://indycog.org/indycompletestreets (last visited Sept. 2, 2014).

$90 \mathrm{Id}$.

91 SMart Growth Am. \& NAT'L Complete Sts. CoAl., supra note 69, at 7-14.

92 Id. 
ordinance adoption, the City shall create individual numeric benchmarks for each of the performance measures included, as a means of tracking and measuring the annual performance of the ordinance. Quarterly reports shall be posted on-line for each of the above measures. ${ }^{93}$

Indianapolis also was considered the top policy regarding "implementation next steps." Overall, Indianapolis received a score of 89.6 out of 100, with Hermosa Beach, CA and Huntington Beach, CA tying for second with a score of 85.6.9495 This study was conducted in 2012 and evaluated all of the complete streets policies in place nationwide. ${ }^{96}$ Indianapolis being ranked number one in the United States shows the degree of success the state as a whole could achieve in terms of combating obesity by promoting physical activity in communities statewide. The language contained in the city's highly successful policy may provide a model template for the development of statewide legislation.

In addition to complete streets, the Indiana Healthy Weight Initiative has partnered with the Indiana Department of Transportation ("INDOT") to fund a program called, "Safe Routes to School."97 INDOT has funded nineteen projects around the state to promote walking and biking to school with more than 3.4 million in awards in 2012.98 The Indiana Healthy Weight Initiative hopes to add fifty schools that will implement infrastructure improvements that promote walking and biking to school by 2020.99 Additionally, Health by Design, INDOT, and the Indiana Department of Health promote walk to school

93 Id. at 14.

94 Id. at 6.

95 Other policies noted on the list for excellence include: Ocean Shores, WA; Northfield, MN; Portland, ME; Oak Park, IL; Trenton, NJ; Clayton, MO; and Rancho Cucamonga, CA.

96 Id. at 1.

97 MEMMER, supra note 61.

98 Id.

99 Id. 
day. 100 This growing Indiana program is another example of how completing Indiana's streets could benefit Hoosiers of all ages, especially school-aged children on the journey to school.

Statewide complete street legislation was proposed in the Indiana General Assembly in 2010, 2011, and 2013 showing that Hoosiers have an interest in implementing statewide legislation.101 By enacting a statewide law, Indiana has a better chance to uniformly fight obesity with complete streets instead of leaving the decision to localities that may not be able to afford, or have the desire to undertake, such efforts for its citizenry. Additionally, a statewide policy could better connect communities within the state, making travel easier without an automobile.

\section{The Empirical Evidence Base for Built Environment and Complete Streets}

Since the 1980s, energy intake of resources such as oil to make gasoline has increased, while human energy expenditure has declined, showing an energy imbalance that mirrors the obesity rate in the United States. ${ }^{102}$ What does this mean? People are less active today than they were decades ago. Overall rates of sports and leisure activity levels have remained constant and even increased in some instances, but this only accounts for a small amount of physical activity. ${ }^{103}$ Physical activity associated with home, work, and transportation has declined due to changes in economic growth, technological advancements, and social change. 104 In the 1950s in the United States, 30\% of Americans worked in high-activity professions. ${ }^{105}$ By 2000, this number fell to $22 \%{ }^{106}$ Additionally, the number of

100 Id.

101 Indiana Complete Streets Coalition, supra note 11.

102 United Health Found., supra note 39.

103 Physical Activity, HARV. ScH. PUB. HeALTH, http://www.hsph.harvard.edu/obesity-prevention-source/obesitycauses/physical-activity-and-obesity/ (last visited Jan. 18, 2014).

104 Id.

105 Id.

106 Id. 
Americans working in low-activity "desk jobs" rose from 23$41 \% .107$ Increased use of automobiles and reduced use of public transportation is another big issue. Driving cars increased from $67 \%$ of all trips to work in 1960 to $88 \%$ in 2000. 108 Decreased levels of activity lead to more sedentary lifestyles, which include watching television, playing video games, and using the computer to accomplish tasks that once required leaving work or home. ${ }^{109}$ More recent evidence indicates the importance of environment in the obesity epidemic and the need for changes in built environment to better facilitate change in lifestyle. ${ }^{110}$

In 2007, Mia Papas and her colleagues published, The Built Environment and Obesity in Epidemiologic Reviews.111 Papas analyzed the relationship between the built environment and obesity. The built environment has been thought to play an important role in influencing obesity by creating a climate that promotes increased energy consumption and a reduction in energy expenditure. ${ }^{112}$ Built environment includes aspects of a person's surroundings that are human-made or modified, unlike natural aspects of the environment. ${ }^{113}$ Aspects of built environment consist of housing, urban development, land use, transportation, industry, and agriculture.114 Assessing the downfalls of the current built environment is helpful to communities looking to implement obesity prevention plans. This can lead to more user friendly streets and community connectedness if the right changes are made.

The article examined the published empirical data for the influence of built environment on the risk of obesity. ${ }^{115}$ The studies that were reviewed required a direct measure of

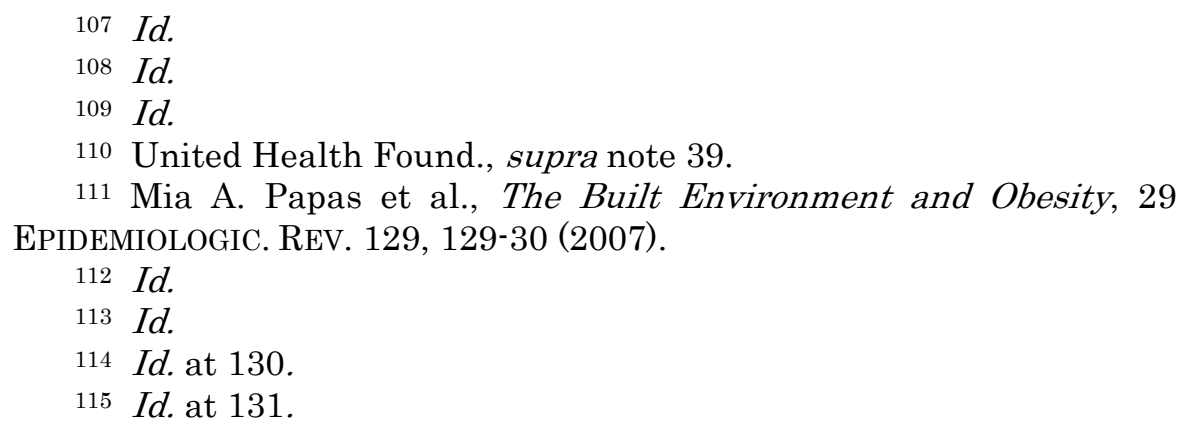


body weight (i.e. body mass index) and at least one objective measure of built environment. ${ }^{116}$ Papas and her colleagues selected twenty studies to review that fit within this criteria.117 Seventeen of the twenty studies reviewed indicated a statistically significant relationship between some aspect of built environment and obesity. ${ }^{118}$ Access to physical activity and access to food outlets were measures of built environment used in these studies. ${ }^{119}$ Additionally, the researchers broke these categories into subsections and inquired about sidewalk availability, proximity to play space/recreational facilities, fast-food restaurant proximity, and daily number of miles driven in a car per day, just to name a few. ${ }^{120}$ Papas concluded that studies are increasingly showing a strong connection between built environment and obesity rates, which provides evidence that built environment, is of importance in community based prevention plans.121 Papas advocated for continued study of the relationship between built environment and obesity, so that communities may have more evidence to conclude that changes in built environment are necessary to curb high obesity rates.

Fazal Khan's recent article, "Combating Obesity through the Built Environment: Is there a Clear Path to Success?" also discusses how built environment can be implemented to curb the detrimental effects of obesity. Khan, like Papas, stated that increasing evidence supports a link between built environment and obesity and wonders what legislators will do when presented with this information. ${ }^{122}$ Changes to the built environment can be expensive at the outset, causing it to be overlooked as a way to lower obesity rates, despite the evidence showing its link to obesity. Cost prohibits legislators from seriously considering change to

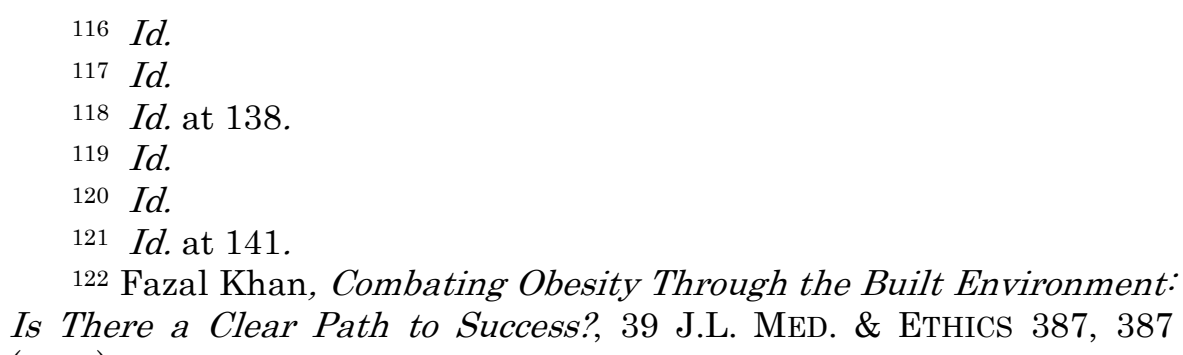


the built environment, even though communities that have already implemented such changes have seen positive results. Studies have shown that children and adolescents with access to parks and recreational facilities near their homes are more physically active than those who lack access. ${ }^{123}$ Another study showed that children who live in neighborhoods without access to parks or green spaces are 1.21 times more likely to be obese. ${ }^{124}$ These studies demonstrate that the environment in which people live does matter and correlates to levels of physical activity. Despite these findings, there exists "no consensus that aspects of the built environment promote obesity."125 Researchers like Papas advocate for further research and conclude that current studies are still in the infancy stage.126 Still this should not discourage built environment advocates, because even with the small number of these studies, communities are implementing change in built environment nationwide through complete street policies.

Harvard School of Public Health published the article, "Environmental Barriers to Physical Activity," which explains how where we live, learn, work, and play impacts how active we are.127 Specifically, how families, worksites, and neighborhoods affect a person's physical activity level. Influencing children to be physically active begins with families. Parents significantly influence how active their children are based on buying sports equipment, taking children to sports practice or other recreational activities, and setting examples as models for healthy living. Studies have shown that paternal activity levels, positive reinforcement, maternal participation, sibling involvement, time spent outdoors, and family income all influence how active a child will become. ${ }^{128}$

123 Id. at 388 .

124 Id.

125 Id. at 389.

126 Id.

127 Environmental Barriers to Physical Activity, HARV. SCH. Pub. HEALTH, http://www.hsph.harvard.edu/obesity-preventionsource/obesity-causes/physical-activity-environment/ (last visited Aug. $23,2014)$.

128 Id. 
Workplace is another huge aspect of determining a person's level of physical activity. Employed adults spend a quarter of their lives at work and are often adversely affected by the pressure and demands of their jobs. ${ }^{129}$ Even though an increased number of Americans are working long hours while sitting at a desk, some employers have implemented on-site gyms or discounts to local gyms within the community. ${ }^{130}$ The built environment also determines how people get to work. People tend to be more active in their commutes if sidewalks, bike lanes, or opportunities to take public transit are available. ${ }^{131}$ Studies have shown that in workplaces with bike storage and cultural support for active commuting, employees are more likely to walk and bike to work. 132 Unfortunately, Americans only use bicycles for $1 \%$ of all trips. ${ }^{133}$ In contrast, people in the Netherlands use bicycles for $27 \%$ of all trips. ${ }^{134}$ However, Americans are increasing walking as a method of transportation. ${ }^{135}$ Walking accounted for $10.5 \%$ of all trips in 2009. This number was up from $8.6 \%$ in 2001.136

Neighborhoods also impact individual activity levels. Neighborhoods with sidewalks, bike lanes, and infrastructure that make crossing the streets safe all encourage physical activity. ${ }^{137}$ Lower income and minority neighborhoods tend to have fewer recreational facilities than wealthier neighborhoods. 138 One study looked at recreation facilities in neighborhoods across Manhattan and the Bronx, greater Baltimore and Forsyth County, North Carolina. ${ }^{139}$ It found that minority neighborhoods were three to eight times more likely to lack recreational facilities than wealthier, predominantly white

\footnotetext{
129 Id.

130 Id.

131 Id.

132 Id.

133 Id.

134 Id.

135 Id.

136 Id.

137 Id.

$138 \mathrm{Id}$.

139 Id.
} 
neighborhoods. ${ }^{140}$ Safe communities also tend to have more active people, as parents feel comfortable letting children play outside and people feel at ease walking around outside. A recent study conducted in Los Angeles found that residents who perceived their neighborhoods as dangerous to have higher BMIs than those who considered their neighborhoods safe. ${ }^{141}$

The biggest problems with linking built environment and obesity are not only that relatively few studies have been conducted where evidence has been conclusive, but also that this research is incredibly complex. Researchers are currently struggling with the vast amount of factors that go into the relationship between built environment and obesity. Some factors that are considered include relationships between community design, patterns of social interaction, the formation of a sense of community cooperation, aspects of safety and security, air and water quality, and mental health. ${ }^{142}$ Another issue is that there are differences in what works for encouraging adults versus children to exercise. "[W]hile we can't safely say that certain changes in community design will lead to increases in physical activity, we can safely say that certain changes in community design will increase opportunities for physical activity," said Susan Handy, environmental science and policy professor at the University of California, Davis. ${ }^{143}$ For these successful strategies to be implemented, governments and communities must work together, as prevention is critical for children, families, communities and workplaces. This is essential, because obesity proves difficult to treat after the fact. ${ }^{144}$

Despite the lack of consensus in the public health community relating built environment and obesity, research consistently shows that increased rates of physical activity help people keep weight steady, while increased rates of a sedentary lifestyle tend to make people gain weight over

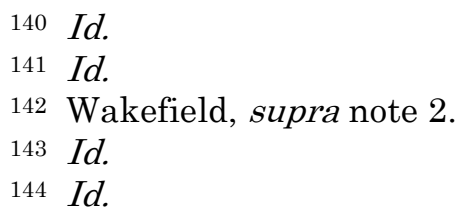


time. ${ }^{145}$ In a study conducted by Cris Slentz and others, 175 adults were randomly assigned to either the control group that received no exercise instruction, or to one of three exercise regimens. ${ }^{146}$ Low-intensity participants walked about twelve miles per week, medium-intensity participants jogged about twelve miles per week, and high-intensity participants jogged about twenty miles per week. ${ }^{147}$ All study volunteers were asked to stick to their regular diets. ${ }^{148}$ After six months of participation in the study, researchers found that subjects in the high-intensity exercise group lost abdominal fat, whereas those assigned to the low and medium-intensity exercise groups did not. ${ }^{149}$

Even though this specific study found that the highintensity group reaped the greatest benefits in the study, increasing physical activity of any kind and duration is a step in the right direction. Researchers believe that any kind of physical activity can prevent obesity in a number of ways. First, physical activity increases a person's energy expenditure, which helps them stay in energy balance or even lose weight. 150 Next, physical activity decreases fat around the waist, and total body fat, which slows the development of abdominal obesity. ${ }^{151}$ Last, physical activity reduces depression and anxiety, which may motivate people to increase physical activity levels after discovering its many benefits. ${ }^{152}$ Unfortunately, individual choice is not the only influence of physical activity. The built environment (buildings, neighborhoods, transportation systems, and other human made elements of the landscape) influences how active people are. ${ }^{153}$ For example, people are

145 Environmental Barriers to Physical Activity, supra note 127.

146 Cris A. Slentz et al., Inactivity, Exercise, and Visceral Fat. STRRIDE: A Randomized, Controlled Study of Exercise Intensity and Amount, 99 J. APPLIED. PHYSIOLOGY. 1613, 1613-1618 (2005).

147 Id.

148 Id.

149 Id.

150 Frank B. Hu, Physical Activity, Sedentary Behaviors, and OBESITY 301-19 (2008).

151 Id.

$152 I d$.

153 Environmental Barriers to Physical Activity, supra note 127. 
more likely to be physically active if they live near parks and playgrounds, in neighborhoods with sidewalks or bike paths, or close enough to work, school, or shopping that they can travel to on bike or on foot. ${ }^{154}$ People tend to be less active if they live in areas of suburban sprawl, where there are fewer opportunities for recreation. ${ }^{155}$ These studies show that our surroundings and state and local policies shape how active people are in their daily lives. Lack of activity is no doubt a major contributing factor to the obesity epidemic. ${ }^{156}$ Making communities "activity friendly" is a way to combat this issue. ${ }^{157}$ This includes opportunities for walking and biking, parks and playgrounds, and safe neighborhoods. ${ }^{158}$ Complete streets is an effective policy that could increase physical activity rates in Indiana, by making communities more "activity friendly."

Other states that have adopted statewide complete streets legislation have lower rates of obesity. For example, Colorado was ranked first for low rates of statewide obesity, compared to California ranked at tenth and Vermont ranked eighth. ${ }^{159}$ These states with low obesity rates all have statewide complete streets legislation, indicating how effective change in built environment can be. This also indicates that states with low obesity rates are dedicated to keeping their citizens healthy. The same states ranked above showed high rates of physical activity, with Colorado ranked fourth, California ranked tenth, and Vermont ranked second. ${ }^{160}$ The correlation between changing environments and higher levels of physical activity indicates that statewide complete street policies are at least somewhat effective in increasing physical activity levels and decreasing obesity rates.

Some may argue that states like California, Colorado, and Vermont have cultural differences from Indiana that

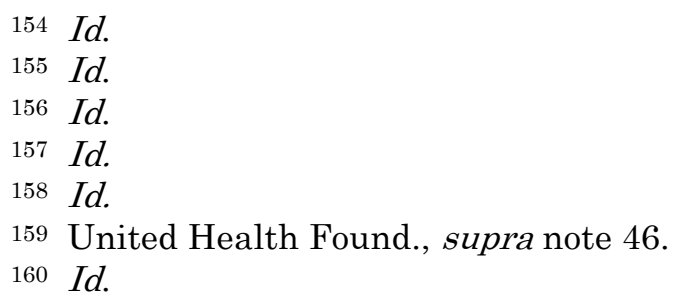


allow for more activity, which causes lower statewide obesity rates. However, this is a myth and generally a stereotype about western and eastern states. Despite the fact that California is generally in a warmer climate than Indiana, this is not true of Colorado and Vermont. The biggest difference between these states with lower statewide obesity rates and statewide complete streets legislation and Indiana is that their communities and leaders made opportunities of physical activity a priority for its citizenry. This includes providing infrastructure, so citizens have alternative means of transportation, other than just driving around in cars.

Additionally, research shows that the way streets, sidewalks, and transportation are designed affects individual rates of physical activity. ${ }^{161}$ A study of Atlanta residents showed that people living in the most walkable neighborhoods were $35 \%$ less likely to be obese, than those living in the least walkable areas. ${ }^{162}$ This suggests that providing the opportunity for physical activity often correlates to actual increased rates of physical activity.

\section{E. Additional Benefits of Enacting Complete Streets Legislation}

Not only do complete streets promote physical activity, but they also promote community growth, which in effect supports the economy. Several local complete streets policies have shown to be successful and transformative for communities economically. Valencia Street in San Francisco had $40 \%$ of merchants report increased sales, while $60 \%$ reported that more area residents were shopping locally due to the complete streets policy. ${ }^{163}$ Barracks Row

161 Nat'l Policy \& Legal Analysis Network, What are Complete Streets? A Fact Sheet for Advocates and Community Members, CHANGE LAB Solutions (Feb. 2010), http://changelabsolutions.org/sites/default/ files/CompleteStreets_FactSheet_FINAL_20100223.pdf.

162 Id.

163 Ind. Cancer Consortium, Complete Streets, IND. CANCER, http://indianacancer.org/wp-

content/uploads/2012/10/completestreets_10_1.jpg (last visited Oct. 7, 2013). 
in Washington D.C., attracted forty-four new businesses and 200 new jobs as a result of new sidewalks, parking spaces, and traffic lights. ${ }^{164}$ Most profoundly, Portland, Oregon reported that a regional trails program saves the city approximately 115 million per year in health care costs. ${ }^{165}$

In addition to improving economic growth, complete streets policies improve safety by reducing crashes through safety improvements, help ease transportation woes, help children, are good for air quality, and make fiscal sense. ${ }^{166}$ Safety is improved by specifically designing infrastructure for pedestrians, including installing raised medians and redesigning intersections and sidewalks. ${ }^{167}$ One study found that implementing complete streets policies reduced pedestrian risk by 28\%. ${ }^{168}$ Streets that provide for multiple travel options reduce traffic jams and increase the total transportation network capacity. ${ }^{169}$ This can help reduce congestion, especially at rush hour times of the day. Children benefit from complete streets policies, which allow them to travel to and from school safely either on foot or by bicycle. Indiana, along with other states, has implemented Safe Routes to School programs that complete streets legislation would benefit.

Further, complete streets policies improve air quality by allowing people to walk, ride bicycles, or take public transportation more easily. Poor air quality in urban areas leads to increases in illnesses like asthma. ${ }^{170}$ If each resident of an American community of 100,000 replaced one car trip with one bike trip just once a month, carbon dioxide (CO2) emissions would be cut by 3,764 tons per year in the

\footnotetext{
$164 I d$.

165 Id.

166 National Complete Streets Coalition: Benefits of Complete Streets, SMART GrowTH AM., http://www.smartgrowthamerica.org/complete-streets/complete-streetsfundamentals/benefits-of-complete-streets/ (last visited Jan. 24, 2014).

167 Id.

168 Id.

169 Id.

170 Id.
} 
community. ${ }^{171}$ This is an example of how complete streets policies can reduce illnesses other than those related to obesity. Lastly, complete streets policies are fiscally smart because integrating sidewalks, bike lanes, transit amenities, and safe crossings into initial design processes saves costs on retrofit projects after the fact.172 Jeff Morales, former Director of Caltrans, stated, "by fully considering the needs of all non-motorized travelers (pedestrians, bicyclists, and persons with disabilities) early in the life of a project, the costs associated with, including facilities for these travelers are minimized." 173

Older Americans also benefit from complete streets policies because as Americans age, they tend to have a harder time traveling around. By 2025, nearly one in five Americans will be aged sixty-five or older. ${ }^{174}$ Complete streets policies provide more opportunities for older Americans to walk places and get out, without the need to drive a car. This is important to a large percentage of aging adults, who become unable to drive and dependent on relatives to get around in the community.

\section{ANALYSIS OF COMPLETE STREETS TO COMBAT HOOSIER OBESITY}

Complete streets are a built environment approach to promoting physical activity in Indiana communities. They are designed to accommodate all users, including: pedestrians, bicyclists, motorists, wheelchair users, and public transit users. ${ }^{175}$ Over the past several years, implementation of complete streets policies has grown increasingly popular on the federal, state, and local levels. Developing complete streets provides users with access to infrastructure that does not require use of an automobile to get to places around the community. Complete streets legislation was proposed in the 2010, 2011, and 2013

\footnotetext{
171 Id.

172 Id.

173 Id.

174 Id.

175 Indiana Complete Streets Coalition, supra note 11.
} 
sessions of the Indiana General Assembly, but did not pass. Still, localities in Indiana are implementing complete street policies as a way to promote community connectedness and physical activity, while fighting continued high obesity rates within the state. This year complete streets legislation has again been proposed. By passing complete streets legislation, Indiana as a whole, could better design its streets to give Hoosiers more opportunities to stay physically active in their communities and reduce obesity related health care costs.

In Indianapolis' recently enacted complete streets ordinance the policy language incorporates the importance of completing streets to combat obesity:

WHEREAS, in Marion County, 40\% of our children are overweight or at-risk for becoming overweight and nearly two-thirds of adults are overweight or obese, and incomplete streets mean many people lack opportunities to be active as part of daily life. ${ }^{176}$

As proposed, statewide complete streets legislation would ensure that the INDOT will design and operate roads with all users in mind.177 This includes pedestrians, bikers, pedestrians, mass transit users, and individuals with disabilities. When a street is "complete" walking and biking are seen as more attractive modes of transportation than just hopping in the car to go somewhere. ${ }^{178}$ As a result, complete streets promote physical activity and make nonmotorists feel like they have a safe alternative for getting to work, school, and back home. Studies have shown that people who live in walkable communities get thirty-five to forty-five additional minutes of moderate physical activity compared to those who do not. ${ }^{179}$ This is just one piece of evidence showing that if people have access to

176 IndianAPOLIS-MARION COUNTY, IND., ORDINANCE ch. 431, art. VIII, $\S 801$ et. seq. (2012).

177 S.B. 450, 118th Gen. Assemb., Reg Sess. (Ind. 2013).

178 Indiana Complete Streets Coalition, supra note 11.

179 Ind. Cancer Consortium, supra note 163. 
infrastructure that promotes physical activity, they are more likely to take advantage of the benefits it offers.

In 2008, California's governor signed into law the complete streets act, co-sponsored by California Bicycle Coalition and the American Association for Retired People (AARP) California. ${ }^{180}$ The law requires cities and counties when updating roadways to account for the needs of all roadway users. Some specific users include bicyclists and elderly individuals, who interest groups represented in support of California's complete streets legislation.

In 2011, Vermont's governor signed a complete streets bill into law. Many interest groups including AARP Vermont and the Vermont Natural Resources Council worked with legislators advocating for the passage of the bill. ${ }^{181}$ The governor noted, "This law will guarantee that we're designing roads that work for the future for older Vermonters, for those who choose to take public transportation, for people who opt to walk to their jobs and errands, and for motorists." 182 One of the provisions of Vermont's legislation provides retiming crossing signals to allow for lower walking speeds. ${ }^{183}$ This makes it easier for elderly people and those who are disabled to get around in the community without using an automobile.

For complete streets legislation in Indiana to succeed, interests groups like Health by Design must collaborate with other groups to show Indiana legislators that a complete streets policy would not only be useful in the state, but largely beneficial. Health by Design is an initiative funded by the non-profit, the Alliance for Health Promotion. Health by Design seeks to increase walking, biking, and public transit options; increase neighborhood, city, and regional connectivity; encourage land-use decision making that promotes public health; and reduce dependency on automobiles. ${ }^{184}$ Health by Design is the major in-state

180 Complete Streets, supra note 12.

181 Gov. Shumlin Signs Complete Streets Bill, supra note 77.

182 Id.

183 Id.

184 Health By Design, http://www.healthbydesignonline.org/ index.html (last visited Aug. 23, 2014). 
group working toward implementation of a statewide complete streets policy. The organization provides complete streets workshops across the state for localities and is responsible for the implementation of the current complete streets policies in place in Indiana. ${ }^{185}$

Like in California and Vermont, Indiana AARP may be interested in supporting increased opportunities of transportation for its members. Indiana Bicycle Coalition is another group likely to support statewide complete streets legislation. Currently, the Indiana Bicycle Coalition has a license plate that can be purchased at the BMV. Bicycle Indiana uses the proceeds from the license plate sales to work to improve bicycling in communities throughout Indiana, support the development of bike lanes and greenways, create and distribute educational safety materials, and advocate safer roads for everyone. ${ }^{186}$ Complete streets in Indiana would definitely benefit the goals of bicyclists and those working in support of the Indiana Bicyclist Coalition.

In 2006, Indiana expanded the Indiana State Trails, Greenways, and Bikeways Plan funding from $\$ 10$ million to $\$ 20$ million to encourage healthy habits, promote tourism, and enhance Indiana's ability to attract new investments and jobs. ${ }^{187}$ This initiative has similar benefits that complete streets seek to address, but differs because trails, greenways, and bike lanes are completely new structures that require new construction. The Indiana Department of Natural Resources, along with the Indiana Department of Transportation, the Governor's Council for Physical Fitness and Sports, the Indiana Department of Tourism and the Indiana Economic Development Corporation produced this trails plan to guide development and expansion of a statewide trails system for transportation and recreational use. ${ }^{188}$ Making streets complete in Indiana would not

185 Indiana Complete Streets Coalition, supra note 11.

186 Indiana Bicycle Coalition, BUREAU OF MOTOR VEHICLES, http://www.in.gov/bmv/2778.htm (last visited Aug. 23, 2013).

187 Ind. DeP'T of Natural Res., Hoosiers on the Move: The Indiana StaTe Trails, GREENWAYs, AND BikEWAYs Plan (2006). 188 Id. 
require entirely new infrastructure like in the trails plan, but rather updating the current streets and sidewalks, which would prove less costly. Also, complete streets are used for transportation, not only recreational use. After the streets have been made "complete," only the costs for routine maintenance are needed, with no further expenditures required. This is unlike most current streets, which require retrofit construction.

Individual communities across Indiana are showing support for the trails. In Fort Wayne, three non-profit trails organizations combined to expand the trails and greenways. Aboite New Trails, the Greenway Consortium, and Northwest Allen Trails have become united as Fort Wayne Trails. Over the past six years, these non-profits independently succeeded in funding forty-one miles of trails in the Fort Wayne area all through grass root support. 189 Fort Wayne Trails' mission is to enhance the community by developing an "ever-expanding" network of trails. ${ }^{190}$ Funding for the trails comes from local businesses, the community, and the state government. ${ }^{191}$ Without this support, the trails could not be sustained.

On the state level, the Greenways Foundation, in partnership with Indiana Trails seeks to promote the growth, enhancement, and use of Indiana trails and greenways. ${ }^{192}$ Trails and greenways are present across Indiana and the Greenways Foundation seeks to expand trails and greenways, so that they are accessible to all Hoosiers. The Greenways Foundation is a non-profit that works with citizens and governmental entities in planning and promoting Indiana trails and greenways. ${ }^{193}$ Organizations like the Greenways Foundation and Fort Wayne Trails want to make Indiana a healthier and a more desirable place to live through the development of trails.

\footnotetext{
189 About $U_{S}$, FORT WAYNE TRAILs, http://fwtrails.org/about/ (last visited Sept. 25, 2014).

$190 \mathrm{Id}$.

191 Id.

192 What We Do, GREENWAYs FOUNDATION, www.greenwaysfoundation.org/about.html (last visited Jan. 1, 2014).

193 Id.
} 
Indiana has made an investment in trails, greenways, and bike lanes, which shows that statewide complete streets legislation is not out of reach for Hoosiers. Complete streets seek to make roadways accessible to all users, which promotes physical activity, economic development, and a more interconnected community. These are parallel goals with Indiana's trails plan. Because the trails plan was successful in receiving more funding, this shows that state legislators understand the importance of giving Hoosiers the opportunity to be more active, promoting economic growth, and the importance of community. Enacting a statewide complete streets law has potential in Indiana if the right interest groups and community members speak up, because it will not be as costly to build and difficult to maintain as with trails, greenways, and bike lanes. 194

INShape Indiana is a state funded program that promotes healthy eating, increasing physical activity, and avoiding tobacco. ${ }^{195}$ More specifically, INShape offers programs to Hoosiers that encourage active lifestyles. Some of the programs offered include: Ready, Set, Walk!; 10 in 10 Challenge; Walk Indiana; IN SHAPE 150; and Summer Fit.196 Ready, Set, Walk! simply provides Hoosiers with walking logs and encourages participants to log miles for twelve weeks. ${ }^{197}$ Additionally, the program provides motivating and overall fitness tips. IN SHAPE 150 encourages participants to meet the 150 minute of moderate aerobic exercise per week goal, by providing new workout plans. ${ }^{198}$ This eight week program provides suggested exercises, along with healthy recipes. ${ }^{199}$ Having complete streets available in Indiana communities could help

194 IND. DEP'T OF NATURAL RES., supra note 187.

195 INSHAPE INDIANA, http://www.inshapeindiana.org/ (last visited Dec. 18, 2014).

196 INShape Programs, INSHAPE INDIANA, www.inshapeindiana.org /207.htm (last visited Feb. 28, 2014).

197 Programs: Ready, Set, Walk!, INSHAPE INDIANA, www.inshapeindiana.org/213.htm (last visited Feb. 28, 2014).

198 Programs: INShape 150, INSHAPE INDIANA, www.inshapeindiana.org/216.htm (last visited Feb. 28, 2014).

199 Id. 
encourage more Hoosiers to participate in programs like Ready, Set, Walk! and IN SHAPE 150.

The National Complete Streets Coalition promotes the implementation of complete streets nationally. The coalition is made up of interest groups including: AARP, the National Association of Realtors, and the American Public Transportation Association. 200 With help and support from the National Complete Streets Coalition, over 500 complete streets policies have been implemented across the United States on state and local levels. ${ }^{201}$ Like Health by Design, the National Complete Streets Coalition provides workshops to communities that focus on foundation laying, policy development, policy implementation, and design considerations. ${ }^{202}$ With support from organizations like Health by Design, the National Complete Streets Coalition, and community members, statewide complete streets legislation is a realistic goal that can be achieved in Indiana.

Some may argue that individual communities around the state are doing enough for Indiana and that statewide complete streets legislation would be costly to taxpayers. First, only $36 \%$ of Hoosiers have access to complete streets currently, which despite its low number, is a step in the right direction. However, localities alone cannot implement sufficient changes statewide to adequately combat the current obesity rates. Statewide complete streets legislation is needed to change current practice and integrate the needs of all road users into everyday transportation planning and design. ${ }^{203}$ By enacting legislation, the policy would gradually create a complete

200 National Complete Streets Coalition, Who We Are, SMART GROWTH AM., http://www.smartgrowthamerica.org/complete-streets/ who-we-are (last visited Jan. 1, 2014).

201 Welcome to the National Complete Streets Coalition, SMART GROWTH AM., http://www.smartgrowthamerica.org/complete-streets (last visited Jan. 1, 2014).

202 National Complete Streets Coalition, Schedule a Workshop, SMART GROWTH AM. http://www.smartgrowthamerica.org/completestreets/get-help/workshops (last visited Jan. 1, 2014).

203 HEALTH By DeSIGN, supra note 71. 
network of streets that serve all Hoosier users. ${ }^{204}$ In the long term, this is more cost effective, because retrofit projects are always more expensive than doing it right the first time. ${ }^{205}$

When Indianapolis implemented its complete streets ordinance, there was increased spending of approximately $5 \%$ of the overall project to add sidewalks and bike lanes. ${ }^{206}$ Even though a small increase in spending occurred, the overall benefits outweigh these costs. Complete streets provides for improved safety, which reduces the number or injuries and fatalities that prove costly.207 Some additional benefits include: the potential for economic development, opportunities for increasing physical activity, reduced traffic congestion, improvements in air quality, and a comprehensive, integrated transportation system. ${ }^{208}$ Specifically increasing physical activity and improving air quality reduces costs in preventable health care for both individuals and the state. Indiana's obesity-attributable health care spending in 2008 was estimated at $\$ 1.9$ billion or $\$ 435$ per adult and is expected to increase to high as $\$ 7$ billion or $\$ 1484$ per adult by $2018 .{ }^{209}$ Studies have shown that increasing physical activity can lower health care costs, as people become healthier by staying active. Even if there are some increased costs with a statewide complete streets policy, the state could save much more in obesity related and overall health care spending.

Other opponents argue that including bike lanes and making streets "complete" takes away from accommodating motorists, who are the predominant users of the streets. They additionally believe that making streets available to all users causes confusion for motorists. Both of these arguments are weak and seek to support the status quo. If streets were made complete, more people would have the

204 Id.

205 Id.

${ }^{206}$ We Have a Complete Streets Ordinance in Indianapolis!, supra note 89 .

207 Id.

208 Id.

209 Ind. State Dep't of Health, supra note 50. 
opportunity to use other methods of transportation than solely using automobiles. Even if drivers are not used to bike lanes, implementing them into the current streets requires drivers to be more vigilant and share the road. The more that bike lanes are available, the less "confused" drivers will be by seeing the lanes and the bicyclists on the road as well.

The cost of complete streets is incorporated into budgeted transportation costs because complete street features are only required when streets are newly built or reconstructed. ${ }^{210}$ Many states across the country are still implementing complete streets policies, despite fiscal constraints. Some successful policies have achieved implementation within the context of the existing transportation budget, sometimes even saving the state money. ${ }^{211}$ Further, complete streets policies make transportation projects more popular, which helps gain support for more transportation funding. ${ }^{212}$ When Minnesota conducted its feasibility study for a statewide complete streets policy, it found that the policy would not significantly increase cost, even while providing valuable safety benefits. ${ }^{213}$ The California State Department of Transportation found that any additional costs of a complete streets policy would be negligible and outweighed by the overall benefits. ${ }^{214}$ These are just two examples of statewide policies that have not found complete streets policies to be overly expensive and burdensome on the state department of transportation's budget.

Additionally, previous research suggests that if Hoosiers have more opportunities to be physically active, obesity and obesity related diseases will likely not increase or even decrease. The health care costs savings would be significant and the positive health implications would be

210 Nat'l Policy \& Legal Analysis Network, supra note 161.

211 Smart Growth Am., Costs of Complete Streets, ENVTL. \& ENERGY STUDY INST., http://files.eesi.org/cs-costs-2-2.pdf (last visited Dec. 18, 2014).

212 Id.

213 Id.

$214 I d$. 
immeasurable. Not only have complete streets been demonstrated to be effective in promoting physical activity and decreasing rates of obesity, but they also have the potential to improve community connectedness overall, resulting in happier communities where people enjoy living and working.

\section{CONCLUSION}

The data shows that obesity is an epidemic sweeping the nation, with no exception in the state of Indiana. If these alarming statistics are going to improve in the future, the state must implement policies that will help citizens increase physical activities and eat healthier in their daily lives. The experiences of other states that have already implemented complete streets legislation suggest that adding such measures in Indiana may positively impact obesity by providing safe travel options for Hoosiers, encouraging greater opportunities to increase the number of pedestrians and bicyclists in our communities. These changes in turn may lead to increased numbers of Hoosiers meeting the 150 minutes per week of vigorous physical activity or the 300 minutes per week requirement of moderate physical activity, helping individuals lose weight and lower BMI. ${ }^{215}$

Unfortunately, if statewide complete streets legislation is again rejected, Hoosiers are more likely to be plagued by the detrimental effects of obesity and the related care costs that go along with the epidemic. As Dr. Gregory Larkin predicted, our health care spending on obesity could skyrocket to $\$ 7$ billion or $\$ 1484$ per adult by 2018 if Indiana fails to take action. ${ }^{216}$ Communities, families, and employers will all be negatively affected with no statewide plan to reduce rates of obesity in Indiana. Enacting complete streets legislation is a form of prevention that may help slow the increasing rates of obesity in Indiana and over time slowly decrease these staggering numbers.

215 HensRUd, supra note 26.

216 Ind. State Dep't of Health, supra note 50. 
Local trends of implementing complete streets in Indiana and the success of the trails, greenways, and bike lanes plan demonstrate to the General Assembly that the state is prepared to move forward with legislation that will reap the health, social, and fiscal benefits that other states are already enjoying. However, this effort must be supported by citizens, community groups, and Indiana noting that if it is to succeed. These people must convince the General Assembly that Indiana is tired of ranking as one of the most obese states in the nation, ready to address this epidemic with open arms, and show lawmakers that complete streets is an essential stride for the future of healthy Hoosiers. One step at a time, Indiana is ready to complete its streets and help Hoosiers become more physically active now and in the future. 